\title{
PREPARATION, IN-VITRO RELEASE AND ANTI- INFLAMMATORY ACTIVITY OF MELOXICAM IN DIFFERENT GEL FORMULATIONS
}

Mahmoud El-Badry

Department of Pharmaceutics, Faculty of Pharmacy, Assiut University 71526, Assiut, Egypt

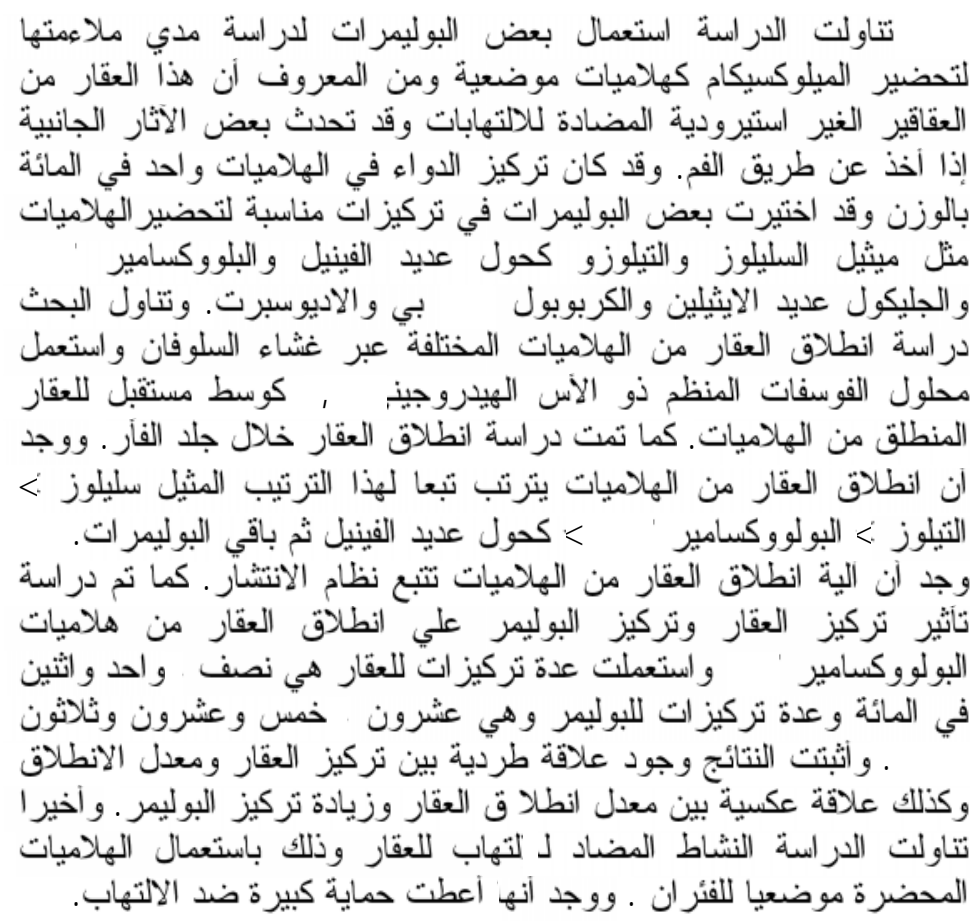

This study was designed to evaluate different polymers to their suitability for formulation as vehicles for topical delivery system. Meloxicam (MX) was incorporated into the gel vehicles in a concentration of $1.0 \% \mathrm{w} / \mathrm{w}$. It is a non-steroidal anti-inflammatory drug (NSAID) of the enolic acid class of compounds.

Polymers used in this study are methylcellulose (MC), tylose (Ty), polyvinyl alcohol (PVA), poloxamer 407 (polo), polyethylene

Received in 23/3/2009, Received in revised form in 31/5/2009 \& Accepted in 1/6/2009 
glycol (PEG), carbopol 974P (Carb. and eudispert mv. (Eud). They are used in a suitable concentration for gel formation.

In-vitro release characteristics of the drug from different gels were carried out using dialysis membrane in phosphate buffer $\mathrm{pH}$ 6.8. The release data were treated with various kinetic principles to assess the relevant parameters.

The general rank order of $M X$ release was $M C>T y>$ polo > $P V A>$ other gel forms. The results also showed that, the release of drug from the prepared gels obeyed the diffusion model (Higuchi's equation).

The influence of some formulation and processing variables (initial drug concentration of 0.5, 1.0 and 2.0\% w/w, poloxamer 407 concentration of $20,25,30 \% \mathrm{w} / \mathrm{v}$ in the aqueous gel formulation) on the release patterns have been studied. The results revealed an inverse correlation between the drug release rate and the poloxamer 407 concentration and direct correlation between the drug release rate and the initial drug concentration.

The anti-inflammatory activity of the drug in different gel formulations was studied using carrageenan induced rat paw edema method. The results obtained show an excellent antiinflammatory activity on rat paw edema.

\section{INTRODUCTION}

Non-steroidal anti-inflammatory drugs (NSAIDs) are widely used for long-term treatment of chronic rheumatic diseases such as rheumatoid arthritis, osteoarthritis and ankylosing spondylitis. Meloxicam (MX) is an NSAID of the enolic acid class of compounds. In recent years, it was selected for pharmaceutical development because it exhibits a high potency in animal tests as potential anti-arthritic action, and has a wide spectrum of anti-inflammatory activity $^{1-4}$. However, when orally administered non selective NSAIDs may adversely affect the gastrointestinal tract and can even reduce the life expectancy of patients with rheumatoid arthritis $5 \& 6$.

Topical products are important class of drug delivery systems and their uses in the therapy become more widespread. The purpose of topical dosage form is to conveniently deliver drugs to localized area of the skin ${ }^{7}$.

Considering the fact that most inflammatory diseases occur locally and near the surface of the body, topical application of NSAIDs on the inflamed site can offer the advantage of delivering a drug directly to the disease site and producing its local effects. This occurs while avoiding gastric irritation and reducing adverse systemic effect ${ }^{8}$.

Meloxicam (MX) is a water insoluble drug, so hydrogel may be 
excellent vehicles for topical delivery of this drug.

The purposes of the present study are to formulate meloxicam (MX) in different gel forms, to determine the in-vitro release of the drug from these formulations through cellophane membrane and through rat skin, to study the effect of initial drug concentration on the release rate, the effect of polymer concentration of drug release and lastly to study the anti-inflammatory activity of these forms on the paw edema in rats.

\section{EXPERIMENTAL}

\section{Materials}

Meloxicam (MX) was kindly provided by Medical Union Pharmaceuticals (MUP) Co., AbuSultan, Ismailia, Egypt. Methylcellulose (Dow chemical Co. USA), Carbopol 974P (BF. Goodrich Chem. Co. USA), Eudispert mv (Rhom Pharma, GmbH, Darmstadt, Germany), Ploxamer 407 (Sigma, USA), Tylose (Clariant $\mathrm{GmbH}$, Wiesbaden, Germany), Polyethylene glycol (Merck-Schuchardt, Munchen, Germany), Polyvinyl alcohol (BDH, England). Triethanolamine, sodium dihydrogen orthophosphate (ELNaser Chemical Co. Egypt). Semipermeable membrane tube (cutoff 1500) (Spectra membrane tubing No. 1) was from Spectra Medical Industries Inc. (Los Angeles, CA, USA). All other chemicals are of pharmaceutical grades.

\section{Apparatus}

Electronic balance (Percisa 205A, Oerlikon AG, Zurich, Switzerland), Magnetic stirrer with hotplate (Gallenkamp, England), pH-meter (Jenway, Ltd. UK), UVspectrophotometer (Schmidzu-50-02, Kyoto, Japan). Dissolution tester (Erweka DT-06, Duesseldorf, Germany).

\section{Methods \\ Preparation of gels}

Meloxicam (MX) gels $(1.0 \% \mathrm{w} / \mathrm{w})$ were prepared by different methods according to the polymer used.

\section{Preparation of poloxamer 407 gel}

Poloxamer 407 gel $(25 \% \mathrm{w} / \mathrm{v})$ was prepared by the cold method described by Yong et al. ${ }^{9}$. The weighed amount of the polymer was slowly added to water with gentle mixing. The mixture was left in refrigerator $\left(4^{\circ} \mathrm{C}\right)$ overnight to complete dissolution of the polymer. After the formation of a clear viscous solution, a methanolic solution of the drug was added to the cold solution and mixed very gently with a glass rod. The solution was left at room temperature until a clear gel was formed.

\section{Preparation of carbopol 974P gel}

Carbopol 974P gel $(2.0 \% \mathrm{w} / \mathrm{v})$ was prepared by method adopted by Shin et al. ${ }^{10}$. Carbopol was added gradually to water with gentle mixing, ethanolic solution of drug was added. The gel was spontaneously formed by addition of few milliliters of triethanolamine. 


\section{Preparation of eudispert $\mathbf{m v}$ gel}

Eudispert mv $(5.0 \% \mathrm{w} / \mathrm{v})$ was sprinkled gradually to the water; ethanolic solution of drug was added with gentle mixing. Few milliliters of triethanolamine were added until a gel was obtained.

\section{Preparation of methylcellulose and tylose gels}

The weighed amount of the powder (methylcellulose $5.0 \% \mathrm{w} / \mathrm{v}$ or tylose $2.0 \% \mathrm{w} / \mathrm{v}$ ) was mixed gently to the hot water. Stirring was continued until no lumps were observed; ethanolic solution of drug was added and the content left overnight in refrigerator $\left(4^{\circ} \mathrm{C}\right)$ to complete solubility and gel formation.

\section{Preparation of polyvinyl alcohol gel}

The weighed amount of polyvinyl alcohol $(15 \% \mathrm{w} / \mathrm{v})$ was added to the water and mixed very gently till complete dissolution of the powder; ethanolic solution of drug was added with continuous stirring till gel formation.

\section{Preparation of polyethylene glycol gel}

The polyethylene glycol gel was prepared using the heat and mechanical incorporation method. Polyethylene glycol of MW 1000 and 600 in ratio $(1: 2 \mathrm{w} / \mathrm{w})$ was placed in a beaker and heated on water bath till complete mixing and stirred until congealed. The ethanolic solution of drug was added and the contents were mixed gently to produce the final gel.
The prepared MX gel formulations were inspected visually for their clarity, homogeneity and phase separation.

\section{In-vitro release of meloxicam (MX) from different gel formulations}

In-vitro release of the drug from different gel formulations was evaluated using semipermeable membrane tube as reported by Park et $a l .{ }^{11}$. One gm of gel form was inserted carefully into semipermeable membrane tube; both sides of the tube were tied up with a thread to prevent leakage. The semipermeable membrane tube was then placed in a dissolution tester. Release test was performed at $37^{\circ} \mathrm{C} \pm 0.5$ using the paddle method at $50 \mathrm{rpm}$ with $500 \mathrm{ml}$ phosphate buffer ( $\mathrm{pH} 6.8$ ).

Aliquots $(5.0 \mathrm{ml})$ were withdrawn at specific time intervals and filtered. The filtrate was measured spectrophotometrically at maximum wave length $362 \mathrm{~nm}^{12}$ against blank similarly treated using blind gel. The release medium kept constant by adding a fresh buffer to the release media. All experiments were carried out in triplicate and the average values were calculated.

\section{Effect of drug concentration on the release profile from poloxamer gel}

The release profile of $\mathrm{MX}$ from the poloxamer 407 gel formulation $(25 \% \mathrm{w} / \mathrm{v})$ containing different concentration of the drug $(0.5,1.0$, $2.0 \% \mathrm{w} / \mathrm{w})$ was studied to show the effect of drug concentration on the release from gel form. 
Effect of polymer concentration of the gel on the release of the drug

The release profile of MX from the poloxamer 407 gel formulation (20, 25 and $30 \% \mathrm{w} / \mathrm{v})$ containing $(1.0 \% \mathrm{w} / \mathrm{w})$ of the drug was studied to show the effect of polymer concentration on the release from gel form.

\section{Mathematical treatment of the data}

The in-vitro release data of MX from the investigated gel formulations was studied by curve fitting method to different kinetic models of zeroorder, first-order, Higuchi and Korsmeyer-Peppas models.

- Zero-order release:

$$
\mathrm{M}_{\mathrm{t}} / \mathrm{M}=\mathrm{k}_{0} \mathrm{t}
$$

- First- order release:

$$
\operatorname{Ln}\left(1-\mathrm{M}_{\mathrm{t}} / \mathrm{M}\right)=-\mathrm{k}_{1} \mathrm{t} \ldots \ldots \ldots \ldots \text { eq. } 2
$$

The Higuchi square root of time model has been derived from Fick's first law of diffusion and is suited for the modeling of drug release from a homogeneous planar matrix, assuming that the matrix does not dissolve ${ }^{13}$ :

$\left(\mathrm{M}_{\mathrm{t}} / \mathrm{M}\right)^{2}=\mathrm{kt}$ eq. 3

The Korsmeyer-Peppas equation ${ }^{14}$;

$\mathrm{M}_{\mathrm{t}} / \mathrm{M}=\mathrm{kt}^{\mathrm{n}}$ .eq. 4

Where:

$M_{t} / M$ : is the fraction of released drug at time t.

$\mathrm{k}_{0}$ : is zero-order release rate constant. $\mathrm{k}_{1}$ : is first-order release rate constant. $\mathrm{K}$ : is a characteristic release rat constant.
It was used to study drug release mechanism by analyzing $\mathrm{n}$ as the diffusion exponent. According to this equation if $\mathrm{n} \leq 0.5$ it is a Fickian mechanism, $0.5<\mathrm{n} \leq 0.8$ it is NonFickian and if $0.8 \leq \mathrm{n} \leq 1$ a zero-order mechanism is governing the drug release mechanism from the gel ${ }^{15}$.

\section{In-vitro skin permeation studies}

A skin permeation study of MX gel formulations was carried out using abdominal skin of female mice $^{16}$. To obtain skin, animals were sacrificed. Hair on the dorsal side of the animal was removed with the help of a $0.1 \mathrm{~mm}$ animal hair clipper, in the direction of tail to head. Dermal part of the skin was wiped three times with a wet cotton swab soaked in isopropanol to remove any adhering fat material. Then, treatment of the dermal side with phosphate buffer $\mathrm{pH}$ 6.8 for $6 \mathrm{hrs}$, to equilibrate the membrane, was done before starting the diffusion experiment. Skin was stretched over one end of an openended glass tube. The tube was immersed in a $400 \mathrm{ml}$ beaker containing $200 \mathrm{ml}$ of phosphate buffer $\mathrm{pH} 6.8$ and kept in vertical position so that the membrane was just below the surface of the buffer solution. The surface area available for diffusion was $2.51 \mathrm{~cm}^{2}$. The tube (donor) and beaker (receptor) were maintained at $37 \pm 0.5^{\circ} \mathrm{C}$ in thermostatically controlled shaker water bath. The donor compartment was filled with $0.5 \mathrm{gm}$ of gel formulation. At predetermined time intervals (up to $4 \mathrm{hrs}$ ) samples of 2.0 
$\mathrm{ml}$ were withdrawn from the receptor and analyzed spectrophotometrically at $362 \mathrm{~nm}$. The experiment was repeated three times and the average of the three reading was calculated.

\section{Flux calculation}

The cumulative amount of MX released at different time interval, the flux per unit area and time were calculated. Cumulative amount of drug released at the end of $4 \mathrm{hrs}$ and the maximum flux values for different formulations were compared using student t-test at 0.05 level of significance. Lag times were obtained by extrapolating the cumulative amount of drug released versus time curves to the time axis.

\section{Anti-inflammatory activity of MX gel}

Acute inflammatory activity model, carrageenan induced rat paw edema method was applied in this study $^{17 \& 18}$.

Rats weighing about $200 \mathrm{gm}$ were divided into 6 groups each group has 6 rats. The animals of group 1 received placebo gel and group 2, 3, 4, 5 and 6 received methylcellulose, tylose, poloxamer 407, Carpopol 974P and eudispert mv gel formulations, respectively. Inflammation was produced in the rats using $0.1 \mathrm{ml}$ of $1.0 \% \mathrm{w} / \mathrm{v}$ carrageenan solution in saline. This was injected subcutaneously into left hind paw. To evaluate the topical anti-inflammatory activity of the gel formulations, paw edema was initially examined. Thirty minutes later, $200 \mathrm{mg}$ of each gel was applied topically on the edematous paw. The increase in the paw thickness was measured before carrageenan injection (time 0) and 2, $3,4,5$ and 6 hrs after carrageenan administration using a dial micrometer. The percentage swelling of the paw and the percent inhibition of edema were calculated. The data were reported as mean $\pm S D(n=6)$.

\section{Statistical analysis for the obtained results}

Statistical analysis for the obtained results was carried out by the student t-test at 0.05 level of significance.

\section{RESULTS AND DISCUSSION}

Visual inspection of freshly prepared formulae revealed smooth homogenous topical preparations with acceptable spreadability. All prepared gels were clear except polyvinyl alcohol, polyethylene glycol gels, which were slightly opaque. All gels were firm, except methylcellulose gel, which was slightly loose. The poloxamer 407 gel was the most elegant one.

\section{In-vitro release of MX from different gel formulations \\ Effect of vehicle on drug release}

The percentage release of MX from various gel formulations evaluated through $4 \mathrm{hrs}$ period was calculated. The general rank order of the release of the drug was observed to be methylcellulose gel > tylose > pluronic F-127 > PVA > carbopol 927P > eudispert $\mathrm{mv}$ and finally PEG gel. 
It is well known that, the nature of the vehicle has a great influence on drug release. In the present study, different hydrogel bases with different polymer structure were used to compare the release profile of the drug from these vehicles. The release rate of the drug through any base depends on the nature and composition of the individual base ${ }^{19}$. The cellulose derivative and poloxamer 407 exhibited a superior drug release which might be related to vehicle nature and structure. The drug release from these gel formulations (after 4 hrs) was 1.5, 2, 3-folds higher than carbopol 927P, eudispert and PEG gel respectively, this may be due to the affinity of the drug to the gel base.

\section{Kinetic of the in-vitro release studies}

In-order to develop an ideal kinetic model to interpret the release rate various kinetic models were applied to obtain the best fit of the data, namely, zero-order, first-order fashions, Higuchi diffusion mechanism and Korsmeyer-Peppas equation. The confirmation between the different mechanisms depends on the correlation coefficient $(r)$ and diffusion exponent of Peppas equation (n) (Table 1). Release kinetics models are shown in Table 1. The results indicate that, the correlation coefficient of release data fitted to Higuchi model in most cases is higher than other models. Also, in all cases the release exponent of Peppas equation was found to be 0.5 . This indicates that, a Fickian mechanism is dominant and controls the drug release from the gels.

Table 1: Kinetic models of MX release from different gels.

\begin{tabular}{||c|c|c|c|c||}
\hline Gel form & $\begin{array}{c}\text { Zero-order } \\
(\mathrm{r})\end{array}$ & $\begin{array}{c}\text { First-order } \\
(\mathrm{r})\end{array}$ & $\begin{array}{c}\text { Higuchi Model } \\
(\mathrm{r})\end{array}$ & $\mathrm{n}$ \\
\hline Methylcellulose & $0.940 \pm 0.025$ & $0.840 \pm 0.015$ & $0.986 \pm 0.011$ & $0.44 \pm 0.02$ \\
\hline Tylose & $0.990 \pm 0.003$ & $0.945 \pm 0.010$ & $0.997 \pm 0.002$ & $0.45 \pm 0.03$ \\
\hline Poloxamer 407 & $0.989 \pm 0.010$ & $0.896 \pm 0.023$ & $0.998 \pm 0.001$ & $0.48 \pm 0.01$ \\
\hline Polyvinyl alcohol & $0.969 \pm 0.015$ & $0.895 \pm 0.025$ & $0.994 \pm 0.002$ & $0.44 \pm 0.02$ \\
\hline Carbopol 974P & $0.978 \pm 0.010$ & $0.939 \pm 0.021$ & $0.995 \pm 0.004$ & $0.45 \pm 0.03$ \\
\hline Eduspirt mv & $0.965 \pm 0.012$ & $0.885 \pm 0.031$ & $0.994 \pm 0.003$ & $0.43 \pm 0.03$ \\
\hline $\begin{array}{c}\text { Polyethylene } \\
\text { glycol }\end{array}$ & $0.920 \pm 0.011$ & $0.939 \pm 0.022$ & $0.975 \pm 0.005$ & $0.42 \pm 0.02$ \\
\hline
\end{tabular}

- $r$ : correlation coefficient

- $n$ : Release exponent of Korsmeyer - Peppas equation. 
Effect of drug concentration on the release profile of the drug

The release profile of MX from the poloxamer 407 gel formulation $(25 \% \mathrm{w} / \mathrm{v})$ containing different concentration of the drug $(0.5,1.0$, $2.0 \% \mathrm{w} / \mathrm{w}$ ) was plotted according to Higuchi model (Fig. 1). The results showed that, the release of the drug increases with the increase in the loaded drug in the vehicle. Similar results were reported by EL-Gendy $e t$ $a l^{20}$ for release of flurbiprofen from different gel bases. Also, Hassan et $a l^{21}$ reported that, the release of ciprofloxacin- $\mathrm{HCl}$ and norfloxacin from different gel bases is depend on the initial concentration of drug.

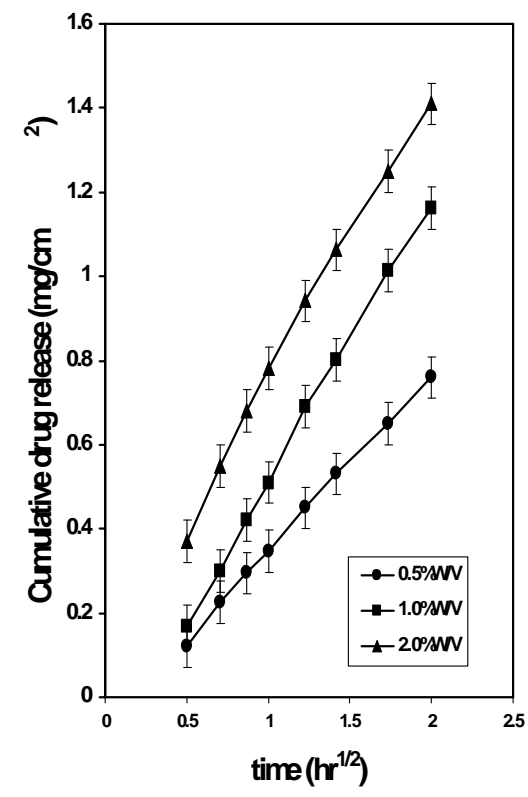

Fig.1: Release profiles of meloxicam from poloxamer 407 gel $(25 \%$ $w / v)$ as a function of initial drug concentration.
Effect of polymer concentration of the gel on the release of the drug

The release profile of MX from the gel bases composed of $20 \%, 25 \%$ and $30 \% \mathrm{w} / \mathrm{v}$ poloxamer 407 presented in Figure 2, the initial concentration was kept at $1.0 \% \mathrm{w} / \mathrm{v}$. In general, it can be seen, as the concentration of poloxamer 407 increase the release rate of the drug decreases (Fig. 2). EL-Gibaly et al. ${ }^{22}$ reported similar results on their study on clotrimazole release from different gel formulation. They reported that, there is an inverse correlation existed between the drug release rate and the concentration of gel forming polymer.

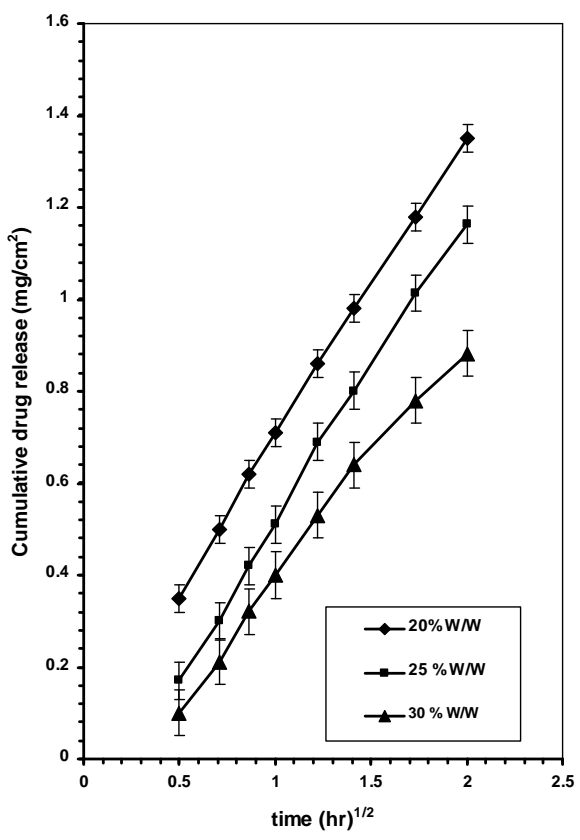

Fig. 2: Release profiles of meloxicam from poloxamer $407 \mathrm{gel}$ as a function of polymer concentration. 


\section{Permeability study}

The release rate of the particular drug substance from the gel bases is primarily dependent on drug affinity to the vehicle, the desirability of the base for enhancing the skin permeation of drug.

The in-vitro study applied in this work employed excised mice skin as membrane to be mounted in diffusion cell. One compartment of the diffusion cell contained MX gel and the other compartment acts as receiver.

Figure 3 shows the mean cumulative amount of MX diffused $\left(\mathrm{mg} / \mathrm{cm}^{2}\right)$ through mice skin for various gel formulations.

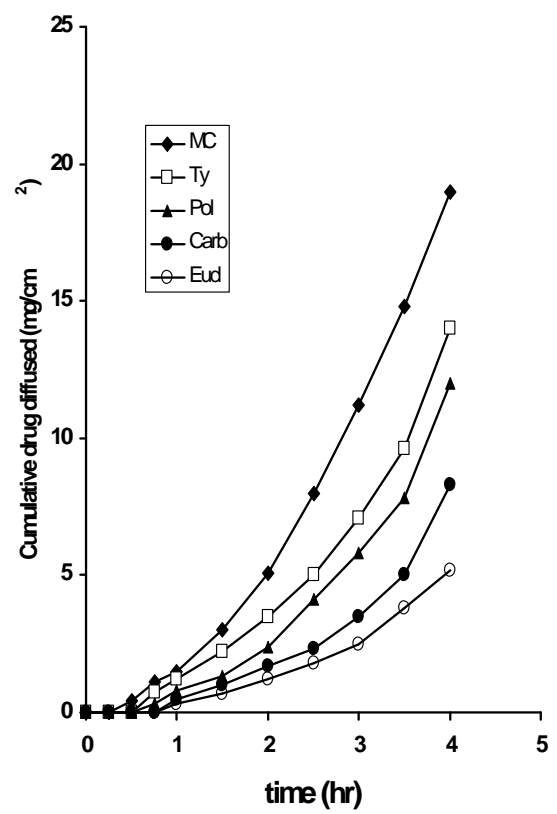

Fig. 3: Permeation profiles of meloxicam from various gel forms across abdominal mice skin.
The values of permeation parameters of MX from various gel forms through skin mice are presented in Table 2. It can be seen from the given data that, clear differences in permeation characteristics were found between gel forms. In all instances, a short lag time $\left(\mathrm{L}_{\mathrm{t}}\right)$ in the range of 0.62-0.86 hr. (depending on the gel form type) was observed in MX permeation through mice skin.

Based on the cumulative amount of the drug diffused at $4 \mathrm{hrs}$, the formulations evaluated in this study showed a decreasing order for their ability to deliver the MX across mice skin membrane as follows: MC $>$ Tyl $>$ Polo 407 > carbo 974P > Eud mv. This is in agreement with Attia et $a l .^{23}$, who reported that, the total flux of piroxicam through rabbit buccal mucosa is depending on the type of gel base and the concentration of gelforming agent.

\section{Anti-inflammatory activity studies} using hind paw edema method

Topical anti-inflammatory activity of semisolid preparations has been reported when applied 1 and $2 \mathrm{hrs}$ before carrageenan treatment as mentioned by Hiramatsu et al. ${ }^{24}$. Clinically, it seems more reasonable to apply the anti-inflammatory topical preparations after the inflammation stimulus ${ }^{25}$. Table 3 illustrates the antiinflammatory activity of different gel formulations on the hind paw of the rats. It is shown that, all the gel formulations have significant effect $(\mathrm{p}<0.05)$ as anti-inflammatory vehicle, but to variable extent 
Table 2: Lag time, cumulative amount of MX and flux values for different gel forms permeated across abdominal mice skin.

\begin{tabular}{|c|c|c|c||}
\hline Gel form & $\begin{array}{c}\text { Lag time } \\
\text { Mean } \pm \mathrm{SD}(\mathrm{hr}) \\
\mathrm{L}_{\mathrm{t}}\end{array}$ & $\begin{array}{c}\text { Cumulative amount } \\
\text { of drug diffused } \\
\text { mean } \pm \mathrm{SD}\left(\mathrm{mg} / \mathrm{cm}^{2}\right) \\
\text { after 4 hrs }\end{array}$ & $\begin{array}{c}\text { Flux of drug } \\
\text { Mean } \pm \mathrm{SD} \\
\left(\mathrm{mg} / \mathrm{hr} . \mathrm{cm}^{2}\right)\end{array}$ \\
\hline Methylcellulose & $0.62 \pm 0.10$ & $19.20 \pm 0.25$ & $1.10 \pm 0.20$ \\
Tylose & $0.68 \pm 0.15$ & $14.50 \pm 0.50$ & $2.20 \pm 0.15$ \\
Poloxamer 407 & $0.71 \pm 0.11$ & $12.10 \pm 1.10$ & $1.26 \pm 0.25$ \\
Carbopol 974p & $0.82 \pm 0.12$ & $8.31 \pm 1.50$ & $2.41 \pm 0.32$ \\
Eudspirt m.v. & $0.86 \pm 0.15$ & $5.15 \pm 0.30$ & $0.89 \pm 0.11$ \\
\hline
\end{tabular}

Table 3: Anti-inflammatory activity of MX in different gel formulations.

\begin{tabular}{|c|c|c|c|c|c|c|}
\hline \multirow{2}{*}{$\begin{array}{l}\text { Rat } \\
\text { group } \\
\text { no }\end{array}$} & \multirow{2}{*}{$\begin{array}{l}\text { gel } \\
\text { Formulation }\end{array}$} & \multicolumn{5}{|c|}{$\%$ Swelling of induced edema and \% inhibition of edema } \\
\hline & & $2 \mathrm{hrs}$ & $3 \mathrm{hrs}$ & $4 \mathrm{hrs}$ & $5 \mathrm{hrs}$ & $6 \mathrm{hrs}$ \\
\hline 1 & Control & $100 \pm 0.5$ & $99.0 \pm 0.5$ & $98.0 \pm 1.0$ & $99.0 \pm 0.6$ & $100 \pm 0.5$ \\
\hline 2 & $\begin{array}{l}\text { Methyl- } \\
\text { cellulose }\end{array}$ & $\begin{array}{c}50.0 \pm 0.5 \\
(49.8) \\
\end{array}$ & $\begin{array}{c}40.1 \pm 0.6 \\
(59.4)\end{array}$ & $\begin{array}{c}35.5 \pm 0.5 \\
(64.6)\end{array}$ & $\begin{array}{c}30.3 \pm 0.4 \\
(69.5) \\
\end{array}$ & $\begin{array}{c}20.5 \pm 0.3 \\
(79.5)\end{array}$ \\
\hline 3 & Tylose & $\begin{array}{c}55.1 \pm 0.4 \\
(45.9)\end{array}$ & $\begin{array}{c}50.5 \pm 2.0 \\
(48.9)\end{array}$ & $\begin{array}{c}45.2 \pm 1.5 \\
(54.2)\end{array}$ & $\begin{array}{c}40.3 \pm 1.2 \\
(58.9)\end{array}$ & $\begin{array}{c}30.5 \pm 1.1 \\
(69.5)\end{array}$ \\
\hline 4 & Poloxamer & $\begin{array}{c}60.2 \pm 0.8 \\
(39.8) \\
\end{array}$ & $\begin{array}{c}55.3 \pm 0.5 \\
(44.1) \\
\end{array}$ & $\begin{array}{c}51.2 \pm 0.7 \\
(49.5) \\
\end{array}$ & $\begin{array}{c}45.1 \pm 0.5 \\
(54.4)\end{array}$ & $\begin{array}{c}40.4 \pm 1.5 \\
(59.6) \\
\end{array}$ \\
\hline 5 & Carbopol & $\begin{array}{c}65.2 \pm 1.5 \\
(35.8) \\
\end{array}$ & $\begin{array}{c}60.2 \pm 2.0 \\
(39.4)\end{array}$ & $\begin{array}{c}55.5 \pm 1.2 \\
(44.5) \\
\end{array}$ & $\begin{array}{c}50.3 \pm 0.9 \\
(49.5) \\
\end{array}$ & $\begin{array}{c}40.5 \pm 2.5 \\
(59.5)\end{array}$ \\
\hline 6 & Eudspirt & $\begin{array}{c}70.2 \pm 0.3 \\
(29.8)\end{array}$ & $\begin{array}{c}65.3 \pm 0.2 \\
(34.5)\end{array}$ & $\begin{array}{c}58.4 \pm 1.1 \\
(42.3)\end{array}$ & $\begin{array}{c}52.6 \pm 1.3 \\
(48.5)\end{array}$ & $\begin{array}{c}45.8 \pm 0.9 \\
(55.3)\end{array}$ \\
\hline
\end{tabular}

Mean \pm SD

- The value between parentheses indicates the \% inhibition of edema.

(inhibition percentage about 29.879.5) over time course studied (1-6 hrs) as compared with control. At the first $2 \mathrm{hrs}$ of the observation methylcellulose gel shows $49.8 \%$ inhibition while eudispert gel was $29.8 \%$. While after 6 hrs, the inhibitory effect was (79.5 and 55.3) for the same gel forms respectively. The rank order of edema inhibition using this method was in the following order MC > Tyl $>$ Polo 407 > carb 974P > Eud mv. This order is similar to that appear in the permeation of drug through rat skin. This means, that there is a correlation between the amount of drug diffused from the various gel formulations and the anti-inflammatory activity (Fig. 4). 


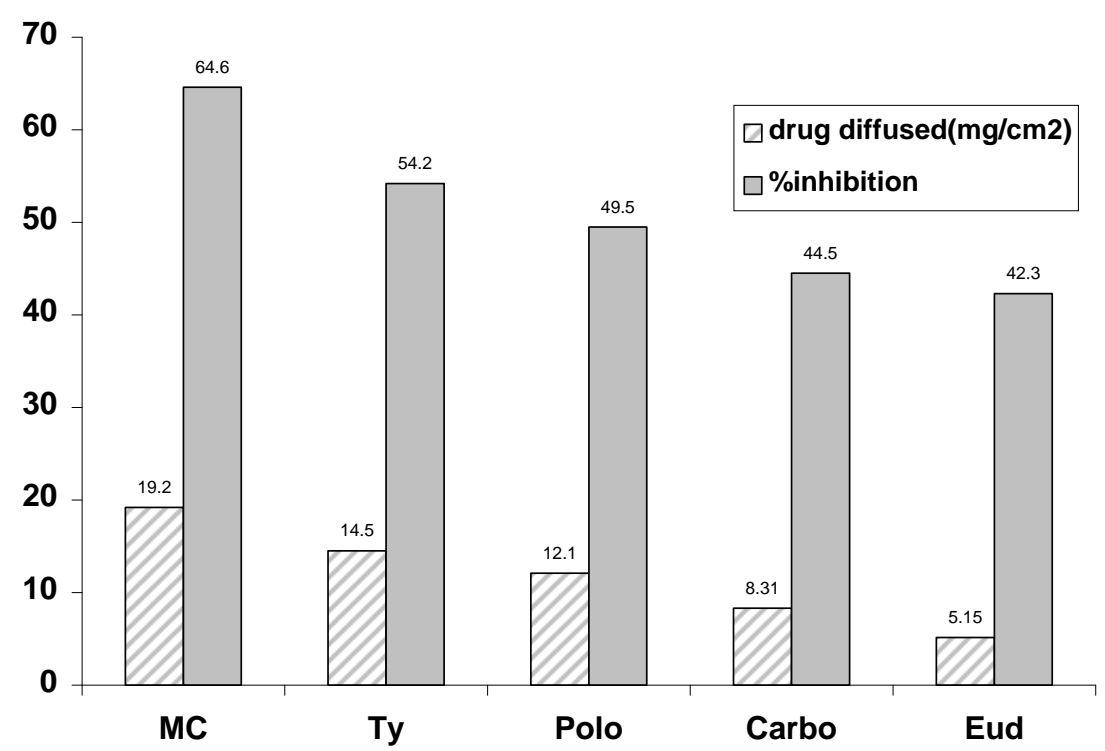

Fig. 4: Correlation between the amounts of drug diffused from the various gel formulations and the anti-inflammatory activity.

\section{Conclusion}

1- The in-vitro study is considered a useful methodology for screening MX topical gel formulations.

2- The release mechanism of the drug from the different gel formulation obeys diffusion mechanism.

3- The amount of drug release of the drug depends on the nature of the polymer used for preparation of gel.

4- There is a direct relationship between the amount of drug released from the poloxamer 407 gel and the initial drug concentration and an inverse relationship with the concentration of the polymer.
5- The MX gel formulations showed an excellent anti-inflammatory activity on rat paw edema.

\section{REFERENCES}

1- B. J. Gates, T. T. Nguyen, S.M. Setter and N. M. Davies, Exprt. Opin. Pharmacother., 6, 2117 (2005).

2- G. Hanft, D. Turck, S. Scheuerer and R. Sigmund, Inflamm. Res., 50, 535 (2001).

3- R. Fleischmann, I. Iqubal and G. Slobodin, Exprt. Opin. Pharmacother., 3, 1501 (2002).

4- S. K. Gupta, P. Bansal, R. K. Bhadwaj, J. Jaiswal and T. Velpandian, J. Pharmacol. Bioph. Res., 15, 105 (2002). 
5- M. W. Whitehouse and M. S. Robert, "Drugs for Pain and Inflammation", In: M. S. Roberts and K. A. Walters (Eds.), Dermal Absorption and Toxicity Assesment, Marcel Dekker Inc., New York, 1998, p. 327.

6- N. M. Davies and N. M. Skjodt, Clin. Pharmacokinet., 36, 115 (1999).

7- E. R. cooper, "Practical Consideration for Topical Drug, Formulations with and without Enhancers", In: A. W. David and H. A. Anton, (Eds.), Topical Delivery Formulations, Marcel Dekker Inc. New York, 1990, p. 10.

8- M. Rafiee-Tehrani and A. Mehramizi, Drug Dev. Ind. Pharm., 26, 409 (2000).

9- C. S. Yong, J. S. Choi., Q.Z. Quan, J.D. Rhee, C.K. Kim, S.J. Lim, K. M. Kim and H. G. Choi, Int. J. Pharm., 226, 195 (2001).

10- S.C. Shin, C-W. Cho and H-K. Choi, Drug Dev. Ind. Pharm., 25, 273 (1999).

11- Y. Park, C. S. Yong, H. Kim, J. Rhee, Y. Oh, C. Kim and $\mathrm{H}$. Choi, Int. J. Pharm., 263, 105 (2003).

12- M. EL-Badry and M. Fathy, Drug Dev. Ind. Pharm., 32, 141 (2006).

13- J. Varshosaz, M. Tabbkhian and Z. Salmani, The Open Drug Delivery J., 2, 61 (2008).

14- R. W. Korsmeyer and N. A. Peppas, "Macromolecular and Modeling Aspects of SwellingControlled Systems", in: T. J.
Roseman and S. Z. Mansdorf (Eds.), Controlled Release Delivery Systems, Dekker, New York, N. Y., 1983, p. 77.

15- H. R. Chuch, H. Zia and C. T. Rhodes, Drug Dev. Ind. Pharm., 21, 1725 (1995).

16- S. A. AL-Suwayeh, Saudi Pharm. J., 11, 46 (2003).

17- Y. Wada, Y. Etoh, A. Ohira, H. Kimata, T. Koide, H. Ishihama and Y. Mizushima, J. Pharm. Pharmacol., 34, 467 (1982).

18- E. Escribano, A. C. Calpena, J. Queralt, R. Obach and J. Domenench, Eur. J. Pharm. Sci., 19, 203 (2003).

19- A. Babar, U. D. Solanki, A.J. Cutie and F. Plakogiannis, Drug Dev. Ind. Pharm., 16, 523 (1990).

20- A. M. EL-Gendy, H. W. Jun and A. A. Kassem, ibid., 28, 823 (2002).

21- M. A. Hassan, F. A. Mohamed and E. A. Sabour, S.T.P Pharma Sci., 13, 195 (2003).

22- I. EL-Gibaly, F. A. Mohamed and M. Shehata, Pharm. Ind., 60, 1088 (1998).

23- M. A. Attia, I. EL-Gibaly, S. E. Shaltout and G.N. Fetih, Int. J. Pharm., 276, 11 (2004).

24- Y. Hiramatsu, S. Akita, P. A. Salamin and R. Maier, Arzniem Forsch., 40, 1117 (1990).

25- E. Escribano, A. C. Calpena, J. Queralt, R. Obach and J. Domenech, Eur. J. Pharm. Sci., 19, 203 (2003). 